\title{
On Traditional Cultural Spirits in Chen Yan's Novel Zhuan Tai
}

\author{
Zhengzhi JIANG \\ School of Language and Cultural Communication, Shangluo University, Shangluo 726000, China \\ 58051362@qq.com
}

Keywords: Chen Yan, Zhuan Tai, traditional cultural spirit.

\begin{abstract}
Chen Yan, a famous writer and playwright from Shaanxi, published a full-length novel Zhuan Tai recently. He pays attention to life of common people. Migrant workers of setting stages for troupes in Xijingcheng are regarded as leading roles. Chen Yan shapes a group of migrant worker images who are characterized by humble status, hard work, low salary, hardship-bearing, kindheartedness, optimistic and gratitude personality, diligence and thriftiness. Traditional cultural spirits of self-improvement, compassion, hardship bearing and responsibility undertaking are shown with warm words. Positive energy is transmitted. The true, the good and the beautiful are expressed. It is an outstanding work which combines ideology and artistic quality perfectly.
\end{abstract}

\section{Introduction}

General Secretary Xi Jinping stressed in Literature and Art Work Symposium that: 'Chinese writers and artists should act as progenitors, pioneers and advocators of social mores. Great practice of people and progress requirements of the times should be written and recorded, faith beauty and nobility beauty are manifested, Chinese spirit is carried forwards, Chinese power is concentrated, and Chinese people in all ethnic groups are encouraged for moving toward the future vigorously' through more textured, moral and warmer literature and art works. [1]7. Chen Yan, a famous writer and playwright from Shaanxi, engaged in creation for more than 20 years as one of more than 70 artists in the symposium. He has published more than ten scripts, such as 'Late Blooms of Roses', 'Big Tree Moves Westwards', 'Xijing Story', etc., films and television programs, such as 'Big Tree and Small Tree', full-length novels, such as 'Xijing Story', prose works 'Must Arrive’, 'As I Was Going along', 'firm expression', 'Chen Yan's Plays', etc. He understands the speech of General Secretary Xi tacitly. Common people are focused in the recently-published full-length novel Zhuan Tai. Migrant workers of setting stages for troupes in Xijingcheng are described. Chen Yan shapes a group of migrant worker images who are characterized by humble status, hard work, low salary, hardship-bearing, kindheartedness, optimistic and gratitude personality, diligence and thriftiness. It is an excellent and warm work for showing traditional cultural spirits. Traditional cultural spirits in the novel are mainly manifested in the following aspects:

\section{Unyielding struggling spirit}

Unyielding struggling spirit is the important characteristic of Chinese traditional culture. It is said in 'copies on silk' that the movement of heaven is full of power. Thus the superior man makes himself strong and untiring. Namely, people should be positive, enterprising, constantly rousing and indomitable regardless of difficulties. Founder of the Confucian Culture-Confucius also advocates the unremitting struggling spirit for realizing own ideals actively. He insisted on 'forgetting, seeking pleasure in order to free himself from care, and not knowing the insidious approach of old age', etc.', which can interpret unyielding fighting spirit well.

The unyielding fighting spirit is also embodied in the novel Zhuan Tai. Diao Shunzi, hero of the novel, has miserable life. He has four wives successively. Tian Miao, his first wife, dislikes poverty and unpromising state of Diao Shunzi who works as a tricycle driver. His first wife elopes with a boss from Guangdong. Zhao Lanxiang-his second wife is virtuous, gentle and considerate, who treats Diao Shunzi and his ex-wife's daughter well. She is good at handling industrious and frugal life. They live 
better, 'four members of the family get along well like an egg without any gap, and he even estimates that they can purchase a house with an area of 120 square meters in Shangyi Road after struggling for several years' [2]285. However, Zhao Lanxiang dies due to cancer. Their savings are used for curing the disease. In addition, they owe many debts. Cai Sufen, his third life, is also a good woman, who is hardworking, responsible, indifferent and careless. Cai Sufen lives more freely compared with his second wife, who withstands repeated abuse of Diao Juhua patiently and can not accept killing of short-leg dog and threat of hanging suicide by Juhua. Kind Cai Sufen is not willing to leave from Shunzi, and she has to leave from Xijingcheng to a really quiet place. His fourth wife is the wife of a stage-setting migrant worker who dies due to hanging.

Diao Shunzi has three daughters. Diao Juhua is the eldest daughter of Diao Shunzi and his first wife. Diao Juhua has ugly appearance and evil temperament, and she is shameless and thuggish, and can't understand and care her father. She spends hard-earned money of her father profligately, and looks down her father who works hard. Han Mei-the second eldest daughter is brought by his second wife. Diao Shunzi regards Han Mei as own daughter and sends her to study in Shangluo University. Diao Shunzi is always proud of Han Mei. However, Han Mei breaks from Diao Juhua due to contradiction with Diao Juhua-his eldest daughter. Han Mei marries in a distant place without negotiation with Diao Shunzi, and stops using former mobile phone number, thereby disconnecting from him. The third daughter is brought by his fourth wife, who was burned severely since childhood. Much money is required for restoring original appearance and living as a common person.

Li Jingze, a famous critic, said that 'a person here called Diao Shunzi does not follow instructions and arrangements, who stands up repeatedly when he encounters difficulties. He not only overcomes difficulties, but also competes with the world endlessly' [3]. Diao Shunzi is defeated by life repeatedly and overcomes difficulties again and again. He has perseverance and struggling spirit. When daughter Juhua asks him about his fourth life, he nodded firmly without margin of negotiation, and he shows gritty courage and determination at the end of the novel. Hardship does not make him depressed, who recovers after setbacks. Diao Shunzi gains courage again and again, who moves on continuously and discovers own happiness and joy.

Chen Yan once said the follows during discussion of his scripts 'Xijing Story', etc.: I want to write a spirit, namely 'Chinese spirit' said by experts. I believe they are self-improvement, self-reliance, self-confidence and self-esteem spirits' [4]. The spirits are inherited in the novel Zhuan Tai. We discover the positive, enterprising and unyielding struggling spirits from the stage setting migrant workers who have humble status, hard work and low salary.

\section{Compassion humane spirit}

Compassion humane spirit is an important spirit in Confucian culture. Confucius said that: 'benevolence means to love others' and 'only good people can be benevolent'. 'Loving fellow men and associate with the virtuous'. Mencius said that: 'he may not dispense with knowledge of Heaven' and 'compassion is benevolence'. He said that 'kiss and Jen, Jen and the love of things'. Confucius emphasized universal love of the masses. Mencius promoted the humanity to love all over the world. The humanity spirit has been inherited by later generations, and it becomes excellent moral tradition of Chinese nation.

A compassion humane spirit is manifested in the novel Zhuan Tai. Diao Shunzi, hero in the novel, is kind and simple with high benevolence. Diao Dajun-his eldest brother enjoys gambling, who is generous and spends money like water. Diao Dajun has less contact with Diao Shunzi, who suffers from pancreatic cancer and eats nothing. Diao Dajun becomes thinner and thinner due to pancreatic cancer and eating nothing, who is received by Diao Shunzi since no people can care him. Diao Shunzi invited an old doctor with high treatment cost, cooks traditional Chinese medicine, and takes care of Diao Dajun until his quiet death. Teacher Zhu in the primary school lives in poverty alone. Diao Shunzi visits the teacher every year, who takes care of the ill teacher carefully till the teacher dies.

Dunzi- employee of Diao Shunzi sleeps behind Guanyin Bodhisattva at night during stage setting in the temple. Dunzi jacks off at midnight, and he ejaculates on Bodhisattva. Therefore, Dunzi is 
discovered. Diao Shunzi notifies Dunzi to escape secretly and accepts punishment instead of Dunzi, namely holding an incense burner on the head, and kneeling down for one night though Diao Shunzi knows the result. The workers are allowed to set the stage, construction cost is deducted, and the distribution process is set back repeatedly. Dunzi should be dismissed. However, his mother suffers from disease for many years; thereby Dunzi is allowed to work here continuously. Diao Shunzi takes care of Dadiao carefully since Dadiao falls in a faint during stage setting once. Some employees with less strength, such as Sanpi, etc., are arranged for some relatively relaxed work. Diao Shunzi treats his employees kindly, and tries his best to assist them. He takes care of his employees if they are ill.

$\mathrm{He}$ is compassionate and wipes tears secretly when he sees the burned and ugly face of Lili-daughter of Colleague Daliao and the sad story of couples Daliao and Zhou Guirong. Diao Shunzi determines to give up the jobs as a tricycle driver, and engages in previous hardworking job with low status-stage setting. Yang Taohua- a man without any relation to Diao Shunzi is allowed specially for earning money by stage setting though Yang Taohua is old. Yang Taohua's son suffers from waist paralysis during coal exploration and needs money for treatment.

Diao Shunzi donates one Yuan the disabled besides the road without legs firstly since he obtains much money from his eldest brother. The disabled is actually poor and does not have leg, Diao Shunzi gives him more five Yuan when he intends to leave away. Diao Shunzi leaves and turns back, the disabled is kowtowing to Diao Shunzi's shadow, Diao Shunzi returns back and gives him ten Yuan again. Diao Shunzi bends over, flattens and places the money in the dirty bowl. The donation money is more and more for three successive times, which can fully show his deep sympathy. He spreads the money flatly rather than throwing to the disabled, which can show his respect to the begging people.

Diao Shunzi is also full of compassion for animals besides people. He does not kill the ants passing through his house. The ants are swept into a hopper by a broom, and poured into the ant team. The ant team is too wide. Diao Shunzi takes big steps to preventing injury on them. Then, he gives ants sesame seeds, rice and water since he heard that the ants can not resist thirst and may die due to long-term water deficiency, we can discover his care to ants. He adopts and treats homeless dogs carefully. Diao Shunzi always takes the dogs in the tricycle since dogs are unattended. He places the tricycle in sunshine for warming the dogs if the weather is cold. We can discover that Diao Sunzi is full of love.

Team Leader Qu, Director Jin, Zhao Lanxiang, Cai Sufeng, etc. have strong empathy besides Diao Shunzi. We discover that there is always warmth force in the cruel and realistic society. We find a group of kind people and a world full of love.

\section{Hard-working perseverance spirit}

Hard-working perseverance spirit is also traditional virtue of Chinese nation. The the Foolish Old Man, who removed the mountains, King Yu tamed the flood and similar ancient stories show the precious quality of Chinese nation. Mencius said that: ' So if God would give an important task to a certain person, the first things he does is to temper his will power, fatigue his muscles and bones, starve his stomach and destitute his body. God would not make any kind of his action satisfactory as he wishes in order to shock his heart, make his temperament persistent and dauntless, and increase his ability'. Chinese nations create countless immortal legends by the hard-working perseverance spirit. China stands town in the east of the world.

The group of migrant workers who live by setting stages for troupes in Zhuan Tai have perseverance spirits of fearing neither hardship nor tiredness, and rush to do dirty and hard work commonly. Stage setting is the hardest work for Shunzi and his colleagues. Stages are set at both daytime and nighttime, and workers live as ghosts, the stages should be installed at night since performing units rehearse at day time basically.'[2]5. The stage setting work lasts for several days once. The workers should work hard even for ten or fifteen days regardless of cold and hot days. They have to work continuously and work overtime for completing the stage setting tasks with the scorching sun directly overhead and cellars. 
Diao Shunzi always pioneers to set stages. 'He rushes to do hard and heavy job without nonsense and command. He implements the uncompleted work of others'[2]394. 'He leads other to work hard, who can set all stages, transportation of half-empty lamps and carrying lamps is the hardest work, and he pioneers to transport lamps'[2]20. 'The lamp box is at least one hundred catties, his legs shake obviously, he insists on transporting the lamps into the light slots'[2]5. Therefore, workers work together, bear respective work, and complete stage setting tasks frequently under his leadership. Diao Shunzi suffers from severe hemorrhoids and frequent bleeding. Severe prolapse is even up to five or six centimeters. However, he still works hard and never relaxes. Diao Shunzi rests for a moment though he feels tired after stage setting, he has to rush to the site if there is an instruction to change the stage, and Diao Sunzi has to work hard continuously.

Injury during stage setting is a commonplace. Some workers lose thumbs and index fingers among stage-setting immigrant workers led by Diao Shunzi. The middle finger of Houzi is cut due to rolling into the motor gears during stage setting for the play 'A Beauty and Peach Blossoms'. Troupe leader Qu discovers that 'Shunzi's hair seems to be caught up from water, his face is dusty, and full of black and white lines by flushing. His face, arms, chest and legs suffer from fine scratches according to short-distance observation. One toe is wrapped by toilet paper, and blood seeps outside' [2]402. However, he doesn't slack off and endures pain which can not be endured by ordinary people. Houzi works rigorously and seriously until stages are set well and props are set well. Once Diao Shunzi carries the background with other people, his foot is punctured by a long rusty nail, which penetrates from arch to instep. He feels painful and sweat rolls down heavily. Diao Shunzi is bandaged in the hospital, and he should rest for several days. However, he insists on returning back to stages immediately and pushing the iron frames during performance. His foot is coated with blood and mouth is even dotted with blood after the work.

It is difficult to demolish the stage after performance. Once they transport troupe background props into the warehouse, 'the warehouse is set on a four-storey building behind the theater; the warehouse of the cast is just located on the fourth floor. A total of nearly 200 iron boxes should be transported upwards; the old building is characterized by narrow and low stairs. The boxes should be backed up one by one. They back the boxes since 11:00 at night to 3:00 in the morning. Shunzi always backs the large boxes, and he can not stand up due to tiredness after he backs the last box'[2]43. Shunzi and his colleagues are always insulted besides work tiredness.

A group of honest migrant workers struggle and work hard for their families and life under the leadership of Diao Shunzi. They show hard-working perseverance spirit, which is admired by people.

IV Responsible professional dedication spirit

Responsible professional dedication spirit also has been advocated in Confucian Culture. Confucius said: 'acting devotedly'. Zhu Xi annotated 'commitment and team working' in 'Rites' that 'professional personnel should devote to own work'. All sayings emphasizes serious and responsible performance in own jobs, and workers should be responsible and devoted. 'Professionalism' is also regarded as an important requirement of occupational ethical conducts of individuals in socialist core values. We also observe the responsible professional dedication spirit from the respectful and lovely migrant workers shaped in the novel Zhuan Tai.

Diao Shunzi not only regards stage setting as a mean and profession of living, but also actually treats stage setting as own carrier. Diao Shunzi stands on the stage alone after workers work for more than ten nights, and his colleagues sleep during large appreciation evening 'Field Carol in Autumn'. He tramples all plates on the stage firstly, and then tramples the player channel one by one for ensuring stability, and then he goes out from the stage'[2]69. Diao Shunzi does not care about his disease and tiredness, and rushes to the stage like flying once he is required on the stage. Stage painting and electric wires are damaged by wind when the performance will be finished. 'Shunzi rushes to the stage, it is a kind of instinct as if the stage belongs to him, the show must go on, and Shunzi should be in the site at the moment'[2]71. The details embody the ownership spirit of Shunzi and his colleagues. They check carefully to ensure no danger even if the work is not supervised and required by other people. However, once the stage should be changed, he has to run to the stage regardless of tiredness. He displays instinct love and responsibility on the stage. 
Director Jin in the troupe and other people also show the dedication spirit besides Shunzi and stage setters. Director Jin pursues excellence in all directed plays as the director in the troupe. She is meticulous on each stage background, each lamp, each sentence and each action of players, etc. She is so strict unreasonably, and reprimands up others viciously. But her severity completely aims at art in order to show the best performance effect of the play. In the novel, the situation of Director Jin is depicted, and she has life ability weaker than retarded women, but has dedication in plays: 'several walls of Director Jin's house are full of various notes and diagrams, namely stage scheduling tables of the play 'Human Being', background prop design drawings and work schedules. Hundreds of tables and drawings are pasted on the wall, which are remembered by her in the mind. Even scheduling of various peach dances is planned at home in advance. People call her 'female workaholic'[2]310. 'A Beauty and Peach Blossoms' and many other plays directed by her can become popular due to such professional and dedicated director. Strong response is produced among audience.

Dedication spirits of bearing responsibility and undertaking obligations of Diao Shunzi, other migrant workers, Director Jin, Team Leader Qu and other leaders of the troupe are reflected in the novel actually and objectively.

\section{Summary}

In short, it is described in Chen Yan's epilogue of Zhuan Tai that I always write biography for small potatoes. I always believe that it is unnecessary to add brilliance to all mighty objects. The significance is unobvious even you can add the brilliance. Therefore, I try to assist, warm and illuminate helpless people in my work, and I especially search a little love of luxury for them. I write works for myself rather than for them. In fact, life should be described, assisted and loved'[2]434. Life of a group of stage-setting migrant workers is described by warm words in the novel Zhuan Tai. The width and depth of social life are displayed. Human kindness and ugliness are revealed, thereby showing the true, the good and the beautiful, and spreading positive energy. Traditional cultural spirits of self-improvement, compassion, hardship bearing and responsibility undertaking are shown by the author with warm words. It softens our mind, which belongs to an outstanding work which combines ideology and artistic quality perfectly and is worth our careful taste and in-depth study.

\section{Acknowledgments}

This work was financially supported by Shangluo Science and Technology Planning Project, and special project of Shangluo College to serve local economic and social development and improve ability; (sk2014-01-29).

\section{References}

[1] Propaganda Department of the Communist Party of China, Reading Textbook of General Secretary Xi Jinping's Important Speech in Literature and Art Work Symposium. Learning Publishing House, 2015.

[2] Chen Yan. Zhuan Tai. Writer Publishing House, 2015.

[3] Jiang Zhengzhi, Wang Fang Qin Qiang: An Elegy of Decline of Traditional Culture. Journal of Shangluo College, 2009, 05:8-12.

[4] Li Jingze. In the World.People's Daily, 2015-10-15.

[5] Wang Shuling, Zhang Yan, Chen Yan: Soul of Modern Drama Should Be Practical. Shaanxi Daily, 2011-04-12.

[6] Jiang Zhengzhi, Tang Mei. On Jia Pingwa's Comprehension to 'A Dream in Red Mansions'. Journal of Shangluo College, 2008, 04:19-22. 